DOI https://doi.org/10.15589/znp2021.2(485).2

УДК $629.5,624.075 .5$

\title{
BUCKLING ASSESSMENT OF SHIP HULL CONSTRUCTION PLATE ELEMENTS UNDER THE SIMULTANEOUS ACTION OF COMPRESSIVE AND SHEAR STRESSES
}

\section{ОЦНКА СТІЙКОСТІ ПЛАСТИНЧАТИХ ЕЛЕМЕНТІВ КОРПУСНИХ КОНСТРУКЦЙ В УМОВАХ ОДНОЧАСНОЇ ДІЇ СТИСКАЮЧИХ ТА ЗСУВНИХ НАПРУЖЕНЬ}

\author{
Leontiy I. Korostylyov \\ leontyy.korostilyov@nuos.edu.ua \\ ORCID: 0000-0002-4370-3270 \\ Yaroslav O. Martychenko \\ Grapua@gmail.com \\ ORCID: 0000-0002-3027-5115
}

\author{
Л. І. Коростильов, \\ докт. техн. наук, професор
}

я. О. Мартиченко, аспірант

\author{
Admiral Makarov National University of Shipbuilding, Mykolaiv \\ Начіональний університет кораблебудування імені адмірала Макарова, м. Миколаїв
}

\begin{abstract}
The buckling assessment of ship's hull construction plate elements, since the beginning of using highstrength steel, is one of the most urgent task. Its considerable complication is caused by presence of cutouts in ship's hull elements, which significantly changes the stress-strain state, as well as the fact that most of hull constructions are under the impact of complex loading, ie the simultaneous action of a number of simple loads. In this paper the problem of buckling assessment of rectangular plate elements with cutouts of ship's hull constructions under the impact of simultaneous action of compression and shear loadings was carried out. Theoretical calculations were performed and a series of boundary curves was constructed, curves which characterize the influence of simultaneous action of the above mentioned loadings on the plate element's buckling, as well as the influence of structural characteristics of such elements on theirs stability, namely the ratio of sides and the presence of centrally located circle cutouts of different sizes. This scientific work is one of a series of studies of the plate elements' buckling of hull constructions, which are currently performed at the Department of Structural Mechanics and Hull Construction at the National University of Shipbuilding named after Admiral Makarov.

Goal. The main aims of this research are to analyze the buckling of rectangular plates under the simultaneous action of compressive $\sigma$ and shear stresses $\tau$. Evaluate the influence of centrally located round cutouts with different sizes on the buckling of such plates and to build boundary curves for each type of calculation.

Method. Using the finite element method, the buckling of simply supported rectangular plates with a centrally located round cutout of different sizes under the simultaneous action of compressive $\sigma$ and shear $\tau$ stresses was numerically investigated. Results. A series of boundary curves is built, the shape of which is closest to the true one. The analysis of the received results and the received analytical formulas for designing of lamellar elements at difficult loading are carried out. The phenomenon of increasing the coefficient of stability of the plate under compression when making large cutouts is shown. Scientific novelty. The obtained results allow a more accurate assessment of the stability of the plate elements under the action of a complex load.
\end{abstract}

Practical importance. The results of scientific research can be used to improve techniques for the design of hull structures. Key words: plate with a cutout; stability; two-component load; structural mechanics of ship hull constructions; boundary curve.

Анотація. Оцінка стійкості пластинчатих елементів корпусних конструкцій суден 3 моменту використання сталі підвищеної міцності є вкрай важливим питанням. Його значне ускладнення зумовлене наявністю в корпусних конструкцій вирізів, що суттєво видозмінюють картину напружено-деформованого стану, а також тим, що більшість корпусних конструкцій перебувають в умовах складного навантаження, тобто одночасної дії деякої кількості простих навантажень. У цій науковій роботі була розглянута проблема оцінки стійкості пластинчатих елементів корпусних конструкцій з вирізами в умовах одночасної дії стискаючих і зсувних напружень. Виконано теоретичні розрахунки і побудовано серію граничних кривих, що характеризують вплив одночасної 


\section{СУДНОБУДУВАННЯ №2г2021}

дії зазначених напружень на стійкість пластинчатого елементу, а також вплив конструктивних характеристик такого елементу на його стійкість, а саме співвідношення сторін та наявність центрально розташованого круглого вирізу різних розмірів. Ця наукова робота є однією із серії досліджень стійкості пластинчатих елементів корпусних конструкцій, що наразі виконуються на кафедрі будівельної механіки і конструкції корпусу корабля у Національному університеті кораблебудування імені адмірала Макарова.

Мета. Метою роботи є виконання аналізу стійкості прямокутних пластин в умовах одночасної дії одноосьового стискаючого $\sigma$ і зсувного $\tau$ напружень та оцінка впливу центральних круглих вирізів різних розмірів на стійкість таких пластин.

Методика. За допомогою метода скінченних елементів чисельно досліджено стійкість шарнірно обпертих прямокутних пластин з центрально розташованим круглим вирізом різних діаметрів під час одночасної дії одноосьового стискаючого $\sigma$ і зсувного $\tau$ напружень.

Результати. Побудовано серію граничних кривих, форма яких найбільш наближена до результатів розрахунку. Проведено аналіз результатів і розроблено формули для проєктування пластинчатих елементів при складному навантаженні.

Наукова новизна. Отримані результати дають можливість більш точно оцінити стійкість пластинчатих елементів під час дії на них складного навантаження $\sigma$ і $\tau$.

Практична значимість. Результати наукових досліджень можуть бути використані для удосконалення практичних методик проєктування корпусних конструкцій суден.

Ключові слова: пластина; виріз; стійкість; двокомпонентне навантаження; гранична крива.

\section{ПОСТАНОВКА ПРОБЛЕМИ}

3 початком використання сталі підвищеної міцності товщина конструктивних елементів корпусу суден почала різко зменшуватись. Разом зі зниженням товщин задля зменшення ваги корпусу судна та забезпечення проведення ремонтних і експлуатаційних робіт у конструктивних елементах почали робити вирізи. Більшість конструктивних елементів знаходиться в умовах складного навантаження, тобто одночасної дії декількох простих типів навантаження. Ці фактори суттєво впливають на напружено-деформований стан та зниження критичних напружень таких елементів і роблять проблему оцінки стійкості однією з визначальних.

Сучасні рекомендації, які представлені в «Правилах $<\ldots>$ » Українського морського регістра судноплавства, DNVGL пропонують виконувати оцінку стійкості пластинчатих елементів окремо від кожного типу простого навантаження [1; 2]. Неврахування фактору одночасної дії простих навантажень значно завищує стійкість таких елементів і призводить до великої похибки у небезпечну сторону.

У роботі виконано оцінку стійкості прямокутних пластинчатих елементів під час одночасної дії стискаючих $\sigma$ і зсувних $\tau$ напружень. Такий напружений стан характерний для більшості плоских елементів поперечного набору, наприклад, стінок флорів, бімсів тощо.

\section{АНАЛІЗ ОСТАННІХ ДОСЛІДЖЕНЬ І ПУБЛІКАЦІЙ}

Проблему достовірної оцінки стійкості конструктивних елементів в умовах складного навантаження було сформульовано ще у $30-x$ роках минулого століття. Вирішення цієї проблеми за допомогою енергетичних теорем і принципів вперше представлено професором П.Ф. Папковичем у вигляді граничної поверхні, яка описує характер взаємодії декількох простих навантажень, що здатні спричинити втрату стійкості пружного конструктивного елемента, та яка розділяє силове поле елемента на зону стійкості та нестійкості. На підставі низки доведених теорем і лем (теореми 2, 4 та 5) він описав форму граничної поверхні і показав, що вона є випуклою і ця випуклість спрямована в бік зони нестійкості [3]. У 60-х роках минулого століття значний внесок у вирішення проблеми стійкості пружних систем при складному навантаженні було зроблено А.С. Вольмиром [4].

Вперше експериментальне дослідження стійкості пластин з вирізами під час одночасної дії зсувного $\tau$ і стискаючого $\sigma$ напружень було виконане професором Л.І. Коростильовим у Миколаївському кораблебудівному інституті [5]. Нині теоретичні й експериментальні дослідження стійкості пластинчатих елементів з вирізами в умовах складного навантаження виконуються на кафедрі будівельної механіки і конструкції корпусу корабля НУК імені С.О. Макарова.

\section{МЕТА ДОСЛІДЖЕННЯ}

Метою роботи є виконання аналізу стійкості прямокутних пластин в умовах одночасної дії стискаючого $\sigma$ і зсувного $\tau$ напружень та оцінка впливу центральних круглих вирізів на стійкість таких пластин.

\section{ОСНОВНИЙ МАТЕРІАЛ}

В умовах двокомпонентного навантаження гранична поверхня трансформується у граничну криву. Задача знаходження істинної форми граничної кривої наближено вирішувалась низкою авторів. У галузевому стандарті [6] було запропоновано наближено представляти таку криву у вигляді прямої. У нашому випадку при одночасній дії стискаючого б і зсувного 
$\tau$ напружень в прямокутних суцільних пластинах із вирізами ця пряма описується такою формулою:

$$
\frac{\sigma_{c r}^{*}}{\sigma_{c r}}+\frac{\tau_{c r}^{*}}{\tau_{c r}}=1,
$$

де $\sigma_{c r}^{*}, \tau_{c r}^{*}$ - ейлереві критичні напруження при одночасній дії $\sigma$ і $\tau$;

$\sigma_{c r}, \tau_{c r}-$ ейлереві критичні напруження при окремо діючих б і $\tau$.

Граничну криву для суцільних пластин при аналогічних навантаженнях А.С. Вольмиром запропоновано в [4] описати такою формулою:

$$
\frac{\sigma_{c r}^{*}}{\sigma_{c r}}+\left(\frac{\tau_{c r}^{*}}{\tau_{c r}}\right)^{2}=1 .
$$

За допомогою метода скінченних елементів було проаналізовано стійкість шарнірно обпертих по крайках прямокутних сталевих пластин $\left(E=2,1 \times 10^{11}\right.$ Па, $\mu=0,3)$ із різними співвідношенням сторін $\gamma=a / b$ товщиною $t=10$ мм та центрально розташованим круглим вирізом висотою $d$. Розрахункова схема прямокутного пластинчатого елемента 3 круглим центральним вирізом при одночасній дії $\sigma$ і $\tau$ представлена на рисунку 1. Ейлереві критичні напруження під час складного навантаження при окремій дії простих напружень були отримані за допомогою таких формул:

$$
\sigma_{\kappa p}=k_{\sigma} \frac{\pi^{2} D}{b^{2} t} ; \quad \tau_{\kappa p}=k_{\tau} \frac{\pi^{2} D}{b^{2} t},
$$

де $k_{\sigma}, k_{\tau}-$ коефіцієнти стійкості при окремій дії $\sigma$ i $\tau$; $\mathrm{D}$ - циліндрична жорсткість пластини.

Під час одночасної дії $\sigma$ і $\tau$ коефіцієнти $k_{\sigma}^{*}, k_{\tau}^{*}$ були отримані за допомогою метода скінченних елементів.

Розрахунок проводився для різних комбінацій $\sigma$ i $\tau$, що призводять до втрати пластиною стійкості. При фіксованих значеннях стискаючого напруження $\sigma$ величина зсувного напруження $\tau$ збільшувалась до моменту втрати пластиною стійкості. Отримані значення $k_{\sigma}^{*}, k_{\tau}^{*}$ представлені на рисунках 2-4.

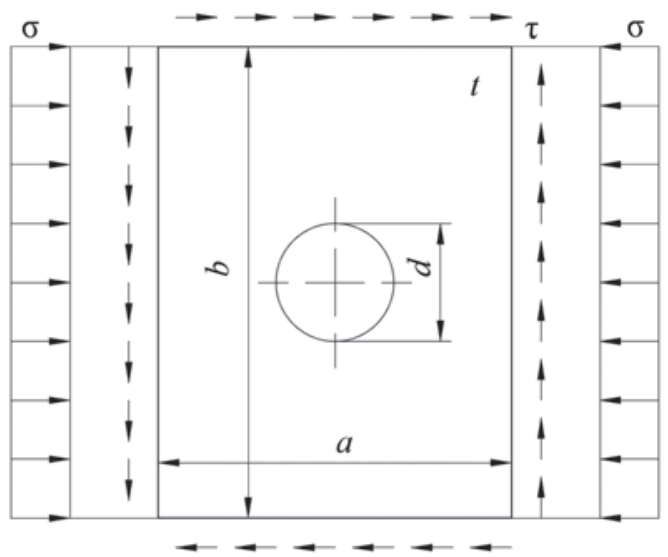

Рис. 1. Розрахункова схема прямокутного пластинчатого елемента 3 круглим центральним вирізом під час одночасної дії $\sigma$ і $\tau$

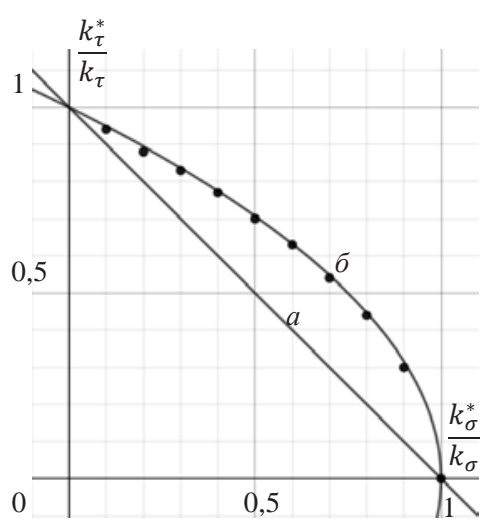

Рис. 2. Представлення граничної кривої під час одночасної дії стискаючих $\sigma$ i зсувних $\tau$ напружень для суцільної квадратної пластини:

a - за формулою (1); б - за формулою (2); •-метод скінченних елементів
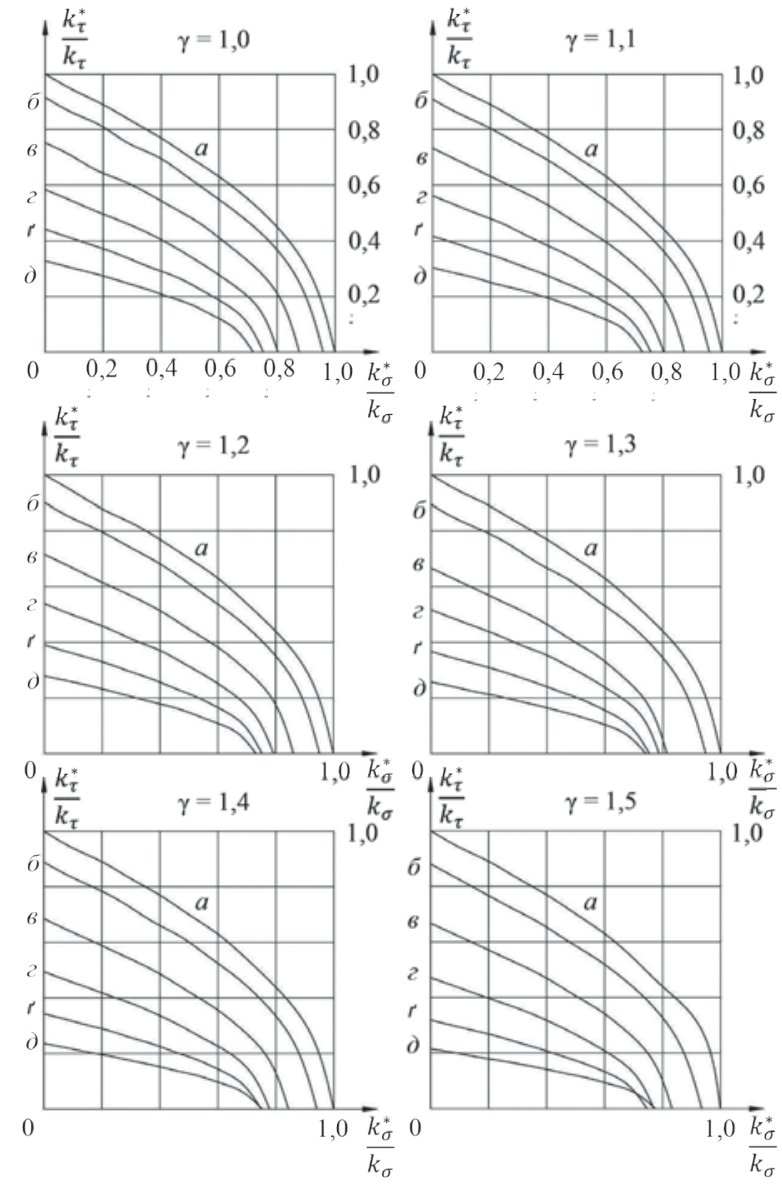

Рис. 3. Граничні криві прямокутних пластин з центральним круглим вирізом з різними співвідношеннями $\delta=a / d$ :

$a-$ суиільна пластина; $\sigma-\delta=0,1 ; в-\delta=0,2 ; 2-\delta=0,3$; $\tau-\delta=0,4 ; \partial-\delta=0,5$

За допомогою апроксимації отриманих точок, що описують граничні криві для різних конструктивних 


\section{СУДНОБУДУВАННЯ №2-2021}

характеристик пластин $\gamma$ та $\delta=d / a$, ці криві можна представити за допомогою такої формули:

$$
\frac{k_{\sigma}^{*}}{k_{\sigma}^{\mathrm{o}}}+\left(\frac{k_{\tau}^{*}}{k_{\tau}^{\mathrm{o}}}\right)^{2}=1,
$$

де $k_{\sigma}^{\circ}, k_{\tau}^{\circ}-$ коефіцієнти стійкості пластини з вирізом при окремій дії $\sigma$ i $\tau$.

Рис. 4. Граничні криві прямокутної пластини з центральним круглим вирізом 3 різними співвідношеннями $\delta$ за формулою (3):

$a-$ суцільна пластина; $\sigma-\delta=0,1 ; в-\delta=0,2 ; 2-\delta=0,3$;

$\tau-\delta=0,4 ; \partial-\delta=0,5 ; \bullet$ та $\times-$ точки, отримані методом скінченних елементів

\section{ВИСНОВКИ}

Виконані розрахунки стійкості прямокутних пластинчатих елементів 3 центрально розташованим круглим вирізом показали, що:
- наближена формула (2) для оцінки стійкості суцільних прямокутних пластин має високу точність;

- наявність вирізу має суттєвий вплив на ейлереві критичні напруження пластини;

- відбувається деяке зростання стійкості пластини під час одноосьового стискання через наявність вирізу великого розміру, тобто із співвідношенням його висоти до меншої із сторін пластини більше, ніж 0,7 (див. рис. 3 при $\gamma=1,4 \ldots 1,5$ ).

Форму граничної кривої при одночасній дії стискаючих і зсувних напружень прямокутних пластин 3 центрально розташованим круглим вирізом 3 високою точністю можна описати формулою (3).

Подальші дослідження будуть спрямованні на оцінку впливу підкріплюючих елементів на відновлення стійкості пластин, послаблених вирізами. Також будуть досліджуватись інші комбінації складного дво- і трикомпонентного навантаження.

\section{REFERENCES}

[1] Rehistr sudnoplavstva Ukrainy (2011). Pravyla klasyfikatsii ta pobudovy morskykh suden. Tom 2. [Rules of classification and building of vessels. Part 2]. Kyiv.

[2] DNV GL (2018). Rules for classification. Ships. Part 3 Hull. Chapter 8 Buckling.

[3] Papkovich, P. F. (1941). Stroitel'naya mekhanika korablya CH.2 [Structural mechanic of the ship. Part 2]. Leningrad: Gosudarstvennoye soyuznoye izdatel'stvo sudostroitel'noy promyshlennosti.

[4] Vol'mir, A. S. (1967). Ustoychivost' deformiruyemykh sistem [Buckling of deforming systems]. Moskva: izdatel'stvo "Nauka".

[5] Korostylov, L. I. (1984). Eksperimental'noye issledovaniye ustoychivosti plastin s vyrezami pri kombinirovannykh nagruzkakh [Experimental research of plates with cutouts buckling under complex loading]. Sbornik nauchnykh trudov NKI, 19-23.

[6] RD 5.1037-80 (1980). Nabor sudovoy. Vyrezy v nabore. Normy i pravila proyektirovaniya [Ship's set. Cutouts in the set. Norms and rules of design].

\section{СПИСОК ВИКОРИСТАНОЇ ЛТЕРАТУРИ}

[1] Регістр судноплавства України. Правила класифікаиї̈ та побудови морських суден. Том 2. Київ. 2011.

[2] DNV GL. Rules for classification. Ships. Part 3 Hull. Chapter 8 Buckling. 2018.

[3] Папкович П.Ф. Строительная механика корабля Ч.2. Ленинград : Государственное союзное издательство судостроительной промышленности. 1941.

[4] Вольмир А.С. Устойчивость деформируемых систем. Москва: издательство «Наука». 1967.

[5] Коростылёв Л.И. Экспериментальное исследование устойчивости пластин с вырезами при комбинированных нагрузках. Сборник научных трудов НКИ. 1984. С. 19-23.

[6] РД 5.1037-80. Набор судовой. Вырезы в наборе. Нормы и правила проектирования. 1980.

(C) Коростильов Л. І., Мартиченко Я. О. Дата надходження статті до редакції: 11.06.2021 Дата затвердження статті до друку: 29.06.2021 